\title{
IMPACT OF TIMING OF ADMISSION IN LABOUR ON SUBSEQUENT OUTCOME
}

\begin{abstract}
Janna JR ${ }^{1}$ Chowdhury SB ${ }^{2}$

To examine the effect of timing at which women admitted either in active or latent phase of spontaneous labour on subsequent outcome. This cross-sectional study was conducted at labour ward, department of Obstetrics and Gynaecology, BSMMU hospital, Dhaka, Bangladesh, from August 2007 to November 2007, where data were collected prospectively. A total of 60 women with term, singletone pregnancy, cephalic presentation with spontaneous onset of labour admitted in labour either in active or latent phase were selected for evaluation. Patients with any medical or obstetric complications, rupture of membrane, antenatally diagnosed foetal anomalies or death and with prior caesarean section were excluded from the study. Patients with cervical dilatation at less than $4 \mathrm{~cm}$ were categorized as latent phase and were in group I. On the other hand, patients with cervical dilatation of $4 \mathrm{~cm}$ or more were marked as in active phase and were allocated in group II. Baseline characteristics were compared. Outcome differences were compared using chisquare $\left(X^{2}\right)$ test, $t$ test, fisher's exact test, $A$ ' $p$ ' value $<0.05$ considered significant.

Duration of labour, mode of delivery, indication for caesarean section, need for oxytocin, labour analgesia, Apgar score $<7$, birth weight of baby, maternal PPH and postpartum hospital stay. A total of 60 patients were enrolled during the study period. Of them 35 patients $(58.3 \%)$ were in group I and 25 patients $(41.7 \%)$ in group II. Duration of labour was more in early admitted group compared to late admitted group (mean \pm SD $17.0 \pm 2.8$ vs $14.3 \pm 2.4$ ). Latent phase women needed more caesarean delivery than active phase women $(62.9 \%$ vs $28.0 \%)$. Dystocia was the main indication for caesarean delivery in the present study which was $68.2 \%$ and $28.6 \%$ in early and late admitted group respectively. Second commonest indication for caesarean section was foetal distress (6 in group I and 5 in group II). Oxytocin for augmentation was used in $62.9 \%$ in group I and $56.0 \%$ in group II and nulliparae women were the one who needed more augmentation $(40.0 \%$ in group I, $36.0 \%$ in group II). Mean foetal weight between two groups did not reach any significant difference $(p>0.05)$. Apgar score $<7$ shows insignificant difference between two groups. PPH was found in $5.7 \%$ cases and all were from group I. Total postpartum hospital stay was significantly longer in group I than group II $(p<0.05)$. $t$ is shown that early admission to the hospital in low-risk women may negatively affect the outcome of labour and are at increased risk of prolonged labour, more need for analgesia, increased rate of caesarean section, increased PPH and postpartum hospital stay.
\end{abstract}

CBMJ 2013 Jan: Vol-02, No-01: P: 21-29

Key words: Latent Phase of labour, Prolonged labour, Caesarean section, PPH, Post partum hospital stay.

\section{Introduction}

The management of labour and its complication is an issue of great importance worldwide. In low-income countries, labour is commonly associated with high levels of foetal and maternal morbidity and mortality. On the otherhand, in the developed world, deliveries are not problem free, although the consequences are of a lesser magnitude to the society as a whole. In both settings, however a careful and methodological approach to the management of labour and its abnormalities will be of benefit to the individual mother and her baby. ${ }^{1}$

Over the last quarter of a century, the caesarean section rate in the USA \& UK has risen to approximately $25 \%$ and over $21 \%$ of deliveries per year respectively. In both settings, dystocia is a common indication. . $^{2,3}$
1. * Dr. Junnu Rayen Janna Assistant Professor, Department of obstetrics \& Gynaecology, Ad-din women`s medical college hospital, Dhaka

2. Professor Saleha Begum Chowdhury Professor and Head Department of Obstetrics \& Gynaecology BSMMU

*Address of correspondence Flat- E8, Mostafa Palace, 1/1, Block- C, Lalmatia, Dhaka- 1207, Bangladesh Mobile: 88-01713-399470

E-mail: junnujanna@yahoo.com 
Women experience onset of labour in a variety of different ways \& cervical anatomy at labour onset is also highly variable from women to women . 4,5. During latent phase, women may experience painful uterine contraction and need a lot of support. High level of pain and anxiety in latent phase are linked with increased

intervention in labour ${ }^{7}$.Presenting to labour in the latent phase is a risk factor for prolonged labour, increased rate of augmentation with oxytocin, epidural analgesia, increased caesarean delivery rate. On the otherhand, later admission increase the rate of spontaneous vaginal delivery. ${ }^{6,9,10,11 .}$ However, early labour assessment program did not find any significant difference regarding caesarean section or instrumental vaginal delivery between two groups. ${ }^{8}$ In addition, there were no difference in infant birth weight, neonatal intubation, $\mathrm{PPH}$ between two groups . ${ }^{10,12}$

There is no consensus from available information as to when to admit a women in labour in order to avoid subsequent adverse outcome. First of all, It needs to define the onset of labour precisely and accordingly determine the timing of admission in labour. Is is better to diagnose labour only when there is evidence of progressive cervical dilatation to indicate entry into the active phase..$^{13}$ It has been proved that initial cervical dilatation rate is useful in early identification of those patient whose deliveries are complicated either by assisted vaginal deliveries or caesarean section both in nulliparous and mulparous women . ${ }^{14,15}$

The present study was an attempt to examine how the outcome of woman changed with timing of admission either in active or latent phase of spontaneous labour in a tertiary hospital setting.

\section{Methods:}

This was a cross sectional observational study, conducted at Labour ward, department of obstertrics and gynaecology, Bangabandhu Sheikh Mujib Medical University Hospital (BSMMU),

Dhaka, Bangladesh, from August 2007 to November 2007.A total of 60 women with term, singletone, cephalic presentation admitted in either active or latent phase of labour were selected for evaluation.Both primi and multigravid women who consented to participate in this study, whose gestational age were(37-42)weeks, spontanous onset of labour with intact membrane at admission were included in this study. Women with prior caesarean delivey, any medical or obstetric complication during pregnancy, antenatally diagnosed foetal anomalies or death, induction of labour and rupture membrane at presentation were excluded from the study. Patients with cervical dilatation at less than $4 \mathrm{~cm}$ were categorized as latent phase and allocated in group -I.On the otherhand, patients with cervical dilatation of $4 \mathrm{~cm}$ or more were in active phase and marked in group-II.

All the case were observed from the date of admission to the date of discharge. History was taken from each and every patient in detail with particular attention to age, parity, socio economic status, obstetrics history, menstrual history,any medical disease and family history. Gestational age was calculated from LMP, where available from early ultrasound findings. Clinically, general ,perabdominal, pervaginal examination done to get the necessary findings. Labour was diagnosed on the basis of: 1 . regular, recurrent, painful uterine contraction, 2 . presence of show, 3. cervical effacement and dilatation. Foetal heart rates were recorded by auscultation in all cases. Uterine contractions were recorded in number per 10 minutes. Foetal monitoring was done by noting foetal heart rate with intermittent auscultation and by observing colour of liquor. Maternal monitoring was done by recording pulse, BP, temperature, urinary output. In every case modified WHO partograph was started after initial assessment on admission. If progress of labour was not satisfactory due to weak inefficient uterine contractions, acceleration of labour was done by oxytocin augmentation. Course of labour was observed in terms of duration of labour, need for augmentation or labour analgesia in each and every case. The labour said to be prolonged when combined duration of 1 st and $2^{\text {nd }}$ stage was more than arbitrary time limit of 18 hours ${ }^{16}$ Dystocia or difficult labour was diagnosed when there was failure to progress of labour with absence 
Original Article

or slow dilatation of cervix including primary dysfunctional labour, secondary arrest disorder, cephalopelvic disproportion, malposition and malpresentation like occipitoposterior, face brow, etc. ${ }^{3}$ Mode of delivery was observed regarding spontaneous or assited vaginal delivery, caesarean section and indication for caesarean section. Immediate foetal outcome was assessed by taking foetal weight, Apgar Score at 1 minute and 5 minutes, need for neonatal resuscitation beyond warming and drying. Maternal outcome was evaluated by noting perineal injury, postpartum haemorrhage $(\mathrm{PPH})$ and total length of hospital stay. $\mathrm{PPH}$ was diagnosed when there was bleeding per vagina which adversely affected general condition of the mother.

Data were collected by standard questionnaire from the allocated patient. Baseline characteristics were compared using independent $t$ test, ch-square $\left(X^{2}\right)$ test, Fisher's exact test. A ' $P$ ' value of $<0.05$ considered significant.

Findings of the study are presented below: A total of 60 patients were allocated in the study. Out of them Table-1 shows that $35(58.3 \%)$ was in group-l and rest $25(41.7 \%)$ was in group-II.

Table II shows (20-24) years age groups and(39-40) weeks of gestation were predominant in both groups, however the mean age and gestational age were almost similar in both groups.

Table I: Categorization of the study subjects on admission $(n=60)$.

\begin{tabular}{|l|c|c|}
\hline Categorization & No. of patients & Percentage \\
\hline Group I & 35 & 58.3 \\
\hline Group II & 25 & 41.7 \\
\hline
\end{tabular}

Table II: Demographic characteristic of the study subjects $(n=60)$.

\begin{tabular}{|c|c|c|c|c|c|c|c|}
\hline \multirow{2}{*}{\begin{tabular}{|l|} 
Characteristics \\
Age (years) \\
\end{tabular}} & \multicolumn{2}{|c|}{$\begin{array}{l}\text { Group I } \\
(n=35)\end{array}$} & \multicolumn{2}{|c|}{$\begin{array}{l}\text { Group II } \\
(n=25)\end{array}$} & \multirow{2}{*}{$\begin{array}{c}t \\
\text { value }\end{array}$} & \multirow[t]{2}{*}{$\mathrm{df}$} & \multirow[t]{2}{*}{$P$ value } \\
\hline & $n$ & $\%$ & $\mathrm{n}$ & $\%$ & & & \\
\hline$\leq 19$ & 0 & 0.0 & 2 & 8.0 & & & \\
\hline $20-24$ & 17 & 48.6 & 11 & 44.0 & & & \\
\hline $25-29$ & 10 & 28.6 & 8 & 32.0 & & & \\
\hline $30-34$ & 8 & 22.9 & 3 & 12.0 & & & \\
\hline$\geq 35$ & 0 & 0.0 & 1 & 4.0 & & & \\
\hline Mean \pm SD & 25.1 & \pm 3.9 & 24.8 & \pm 5.3 & 0.26 & 58 & $0.792^{\mathrm{ns}}$ \\
\hline \multicolumn{8}{|c|}{ Gestational age (wks) } \\
\hline $37-38$ wks & 10 & 28.6 & 10 & 40.0 & & & \\
\hline $39-40$ wks & 20 & 57.1 & 15 & 60.0 & & & \\
\hline $41-42$ wks & 5 & 14.3 & 0 & 0.0 & & & \\
\hline Mean \pm SD & 39.2 & 1.1 & 38.8 & -1.1 & 1.45 & 58 & $0.153^{\text {ns }}$ \\
\hline
\end{tabular}

Table III shows that patients with monthly income of( 5000-10000)taka were more common between two groups.

No significant difference found regarding socio-economic condition between two groups.

Table III: Socio economic condition of the patients $(n=60)$

\begin{tabular}{|l|c|c|c|c|c|c|c|}
\hline $\begin{array}{l}\text { Socio economic } \\
\text { condition }\end{array}$ & \multicolumn{2}{|c|}{$\begin{array}{c}\text { Group I } \\
(\mathrm{n}=35)\end{array}$} & $\begin{array}{c}\text { Group II } \\
(\mathrm{n}=25)\end{array}$ & $\begin{array}{c}\text { Chi } \\
\text { value }\end{array}$ & df & $p$ value \\
\hline & $\mathrm{n}$ & $\%$ & $\mathrm{n}$ & $\%$ & & & \\
\hline$<5000$ & 9 & 25.7 & 8 & 32.0 & 0.28 & 1 & $0.594^{\mathrm{ns}}$ \\
\hline $5000-10000$ & 21 & 60.0 & 15 & 60.0 & 0.00 & 1 & $1.000^{\mathrm{ns}}$ \\
\hline$>10000$ & 5 & 14.3 & 2 & 8.0 & 0.56 & 1 & $0.374^{\mathrm{ns}}$ \\
\hline
\end{tabular}

Group I: Cervical dilatation (os) $<4 \mathrm{~cm}$, Group II: Cervical dilatation (os) $\geq 4 \mathrm{~cm}$, $\mathrm{s}=$ significant, $\mathrm{ns}=$ not significant, $p<0.05$ considered significant .

Table IV shows that Nulliparity was predominant in both groups. 
Table IV: Parity of the patients $(n=60)$.

\begin{tabular}{|l|c|c|c|c|}
\hline \multirow{2}{*}{ Parity } & \multicolumn{2}{|c|}{$\begin{array}{c}\text { Group I } \\
(\mathrm{n}=35)\end{array}$} & \multicolumn{2}{c|}{$\begin{array}{c}\text { Group II } \\
(\mathrm{n}=25)\end{array}$} \\
\cline { 2 - 5 } & $\mathrm{n}$ & $\%$ & $\mathrm{n}$ & $\%$ \\
\hline Nulliparous & 22 & 62.9 & 15 & 60.0 \\
\hline Parous & 13 & $37.1 \%$ & 10 & $40 \%$ \\
\hline Total & 35 & 100.0 & 25 & 100.0 \\
\hline
\end{tabular}

Regarding mode of delivery Table $\mathbf{v}$ shows that normal vaginal delivery was significantly $(p<0.05)$ higher in group II, whereas caesarean section (LSCS) was significantly $(p<0.05)$ higher group I.Among augmented group, caesarean sections were more when they were in group I (59.1\%) and vaginal deliveries were more when they were in group II.

Table V: Mode of delivery of the patients $(n=60)$.

\begin{tabular}{|l|c|c|c|c|c|c|c|}
\hline Mode of delivery & \multicolumn{3}{|c|}{$\begin{array}{l}\text { Group I } \\
(n=35)\end{array}$} & $\begin{array}{c}\text { Group II } \\
(n=25)\end{array}$ & $\begin{array}{c}\text { Chi } \\
\text { value }\end{array}$ & df & P value \\
\hline & $n$ & $\%$ & $n$ & $\%$ & & & \\
\hline Normal vaginal delivery & 13 & 37.1 & 18 & 72.0 & 7.09 & 1 & 0.007 s \\
\hline Caesarean section(LSCS) & 22 & 62.9 & 7 & 28.0 & & & \\
\hline Among augmentated group \\
\hline Normal vaginal delivery & 9 & 40.0 & 10 & 71.4 & 3.21 & 1 & 0.073 Ns \\
\hline Caesarean section(LSCS) & 13 & 59.1 & 4 & 28.6 & & & \\
\hline
\end{tabular}

Table VI shows that majority of caesarean section was done due to dystocia and found $68.2 \%$ in group I and $28.6 \%$ in group II. Fetal distress was $27.3 \%$ in group I and $71.4 \%$ in group II. The difference in indications of caesarean section were not statistically significant $(p>0.05)$ between two groups.

Table VI : Indication of caesarean section of both groups $(n=29)$.

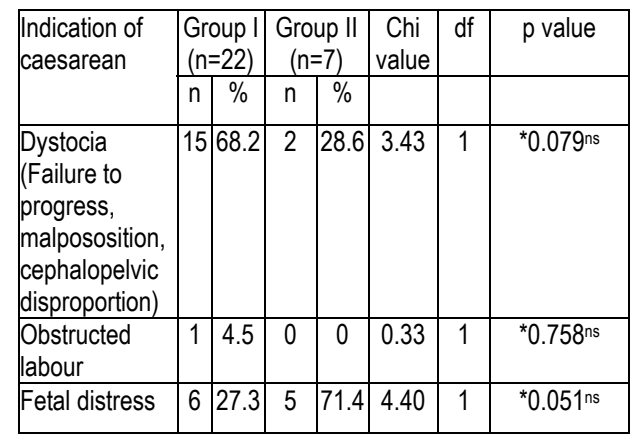

${ }^{*}$ Fisher exact test , $\mathrm{s}=$ significant, ns=nonsignifican,

Group I: Cervical dilatation (os) $<4 \mathrm{~cm}$, Group II: Cervical dilatation (os) $\geq 4 \mathrm{~cm}$, $p<0.05$ considered significant,

Table VII: Summary table.

\begin{tabular}{|c|c|c|c|c|c|c|c|}
\hline \multirow[t]{2}{*}{ Parameters } & \multicolumn{2}{|c|}{$\begin{array}{l}\text { Group I } \\
(n=35)\end{array}$} & \multicolumn{2}{|c|}{$\begin{array}{l}\text { Group II } \\
(n=25)\end{array}$} & \multirow[t]{2}{*}{$\begin{array}{l}\text { Chi / } t \\
\text { value }\end{array}$} & \multirow[t]{2}{*}{$\mathrm{df}$} & \multirow[t]{2}{*}{$p$ value } \\
\hline & n & $\%$ & $\mathrm{n}$ & $\%$ & & & \\
\hline \multicolumn{8}{|l|}{ Duration of labour } \\
\hline$<12$ & 1 & 2.8 & 3 & 12.0 & & & \\
\hline $12-18$ & 20 & 57.1 & 21 & 84.0 & & & \\
\hline$>18$ & 14 & 40.0 & 1 & 4.0 & 10.08 & 1 & $0.001^{\mathrm{s}}$ \\
\hline Mean \pm SD & 17.0 & \pm 2.8 & 14.3 & \pm 2.4 & 3.93 & 58 & $0.001^{\mathrm{s}}$ \\
\hline $\begin{array}{l}\text { Need } \\
\text { augmentation }\end{array}$ & 22 & 62.9 & 14 & 56.0 & 0.285 & 1 & $\begin{array}{c}0.592 \\
\mathrm{~ns}\end{array}$ \\
\hline Need for analgesia & 35 & 100.0 & 20 & 80.0 & 7.64 & 1 & $0.009 \mathrm{~s}$ \\
\hline $\begin{array}{l}\text { Normal vaginal } \\
\text { delivery }\end{array}$ & 13 & 37.1 & 18 & 72.0 & 7.09 & & $0.007 \mathrm{~s}$ \\
\hline Caesarean section & 22 & 62.9 & 7 & 28.0 & & & \\
\hline \multicolumn{8}{|l|}{$\begin{array}{l}\text { Apgar score at } 5 \\
\text { minutes }\end{array}$} \\
\hline$\leq 7$ & 2 & 5.7 & 1 & 4.0 & & & \\
\hline Mean $\pm S D$ & 9.4 & \pm 1.1 & 9.6 & \pm 0.9 & 1.03 & 1 & $0.309 \mathrm{~ns}$ \\
\hline \multicolumn{8}{|l|}{ Weight (kg) } \\
\hline Mean $\pm S D$ & 3.0 & \pm 0.3 & 2.9 & \pm 0.3 & 0.91 & 1 & $0.368^{\text {ns }}$ \\
\hline $\mathrm{PPH}$ & 2 & 5.7 & 0 & 0.0 & & & \\
\hline \multicolumn{8}{|l|}{ Perineal injury } \\
\hline 1st degree & 2 & 5.7 & 0 & 0.0 & & & \\
\hline $2^{\text {nd }}$ degree & 0 & 0.0 & 0 & 0.0 & & & \\
\hline Cervical tear & 1 & 2.9 & 0 & 0.0 & & & \\
\hline Morbidity & 5 & 14.3 & 0 & 0.0 & 3.90 & 1 & $\begin{array}{c}0.059 \\
\text { ns }\end{array}$ \\
\hline \multicolumn{8}{|l|}{\begin{tabular}{|l|} 
Post partum \\
hospital stay (days)
\end{tabular}} \\
\hline Mean \pm SD & 3.0 & \pm 1.6 & 1.8 & \pm 1.4 & 2.96 & 58 & $0.004^{s}$ \\
\hline
\end{tabular}

Group I: Cervical dilatation (os) $<4 \mathrm{~cm}$, Group II: Cervical dilatation (os) $\geq 4 \mathrm{~cm}$, $\mathrm{s}=$ significant, $\mathrm{ns}=$ not significant. $p<0.05$ considered significant. 
Summary Table shows that the mean $( \pm S D)$ duration of labour was $17.0 \pm 2.8$ hours in group I and 14.3 \pm 2.4 hours in group II and the difference was statistically significant $(p<0.05)$. labour $>18$ hours was significantly predominant in group I.

Augmentation was needed predominantly in both groups and the difference was not statistically significant $(p>0.05)$

Analgesia was needed in $35(100.0 \%)$ in group I and $20(80.0 \%)$ in group II. The difference was statistically significant $(p<0.05)$ between two groups.

Regarding mode of delivery Table shows that normal vaginal delivery was significantly $(p<0.05)$ higher in group II, whereas caesarean section (LSCS) was significantly $(p<0.05)$ higher group I.

The mean Apgar score at 5 minute was $9.4 \pm 1.1$ in group I and $9.6 \pm 0.9$ in group II and mean birth weight of was $3.0 \pm 0.3 \mathrm{~kg}$ in group I and $2.9 \pm 0.3 \mathrm{~kg}$ in group II. The difference was not statistically significant $(p>0.05)$ between two groups

$\mathrm{PPH}$ in $2(5.7 \%))$ in group I and none was found in group II. Perineal injury was found $2(5.7 \%)$ and cervical tear was found $1(2.9 \%)$ in group I, whereas no injury was found in group II.

The mean duration of post partum hospital stay was $3.0 \pm 1.6$ days and $1.8 \pm 1.4$ days in group I and group II respectively. The difference was statistically significant $(p<0.05)$ between two groups.

\section{Correlation between cervical dilatation and duration of hospital stay $(n=60)$.}

The cervical dilatation of 60 cases was measured in $\mathrm{cm}$ and the duration of hospital stay was expressed in days. A significant negative correlation was found between cervical dilatation and duration of hospital stay.
The value of Pearson's correlation coefficient was -0.4935 and it is significant $(p<0.05)$. Increase in cervical dilatation, corresponding decrease in duration of hospital stay. Therefore, there was linear negative association between cervical dilatation and duration of hospital stay.

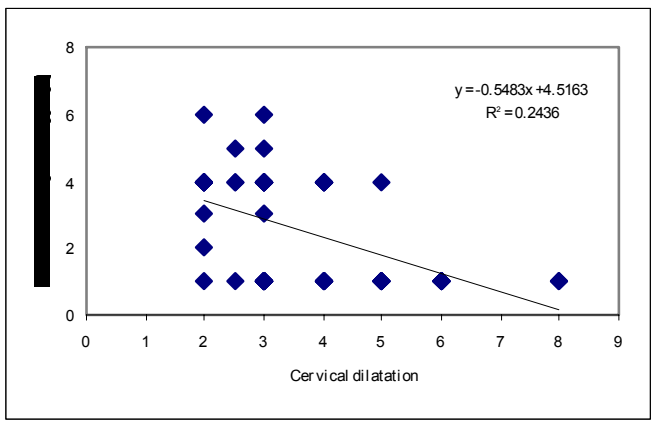

Fig: The scatter diagram shows negative relationship ( $r=-0.4935)$ between cervical dilatation and duration of hospital stay $(n=60)$.

\section{Discussion :}

This study evaluated the labour course of women admitted in latent and active phase of labour to examine the association between timing of admission and subsequent outcome. It limited potentially confounding factors by restricting the data to low-risk term gravidas with spontaneous onset of labour, who were candidate for vaginal delivery. Baseline characteristics were compared.

This study demonstrates that who admitted early in latent phase of labour had a higher risk of prolonged labour, increased need for labour analgesia, increased incidence of caesarean section and increased maternal $\mathrm{PPH}$ and postpartum hospital stay.

Total 60 patients met the eligible criteria in this study population. Out of them $35(58.3 \%)$ patients admitted in early labour at $<4 \mathrm{~cm}$ cervical dilatation and they were in group I. On the other hand $25(41.7 \%)$ patients were in group II, who were admitted in active labour at $\geq 4 \mathrm{~cm}$ cervical dilatation. Two groups were comparable. 
Nulliparity was the highest presentation in this study population. They were predominant inboth group (62.9\% vs $60 \%$ ) and difference was insignificant. Mean age $(25.1 \pm 3.9$ vs $24.8 \pm 5.3)$ and gestational age (39.2 \pm 1.1 vs $38.8 \pm 1.1)$ of the study population were almost similar in both groups and there was insignificant difference regarding economic status between two groups.

These findings reflects that women in latent and active phase of labour were having similar characteristics at admission, allowing the speculation that exposure to the medical system might be responsible for the differences in outcome. To find out the possible explanations of the speculation, a variable number of outcome and related factors were examined.

This study examined the total length of labour and length of time from labour onset to first vaginal examination between the groups of women. The women presenting early did have significantly longer labour compared to late $(17.0 \pm 28$ vs $14.3 \pm 2.4)$ and prolonged labour (labour $>18$ hours) also significantly more in early admission group $(p<0.05)$. This is consistent with findings done by Parvin ${ }^{20}$ and Rahman ${ }^{21}$, where they also found duration of labour $>18$ hours were more in early admitted group than late admitted group $(63.1 \%$ vs $20.5 \%$ and $44.4 \%$ vs $15.2 \%$ respectively). In contrast, Hemminki and Simmuka ${ }^{17}$ explored that women admitted early as compared to late stayed longer in the hospital before delivery but had a smaller total length of labour. The present study included the latent phase in the $1^{\text {st }}$ stage of labour. Thus the duration of this phase might have influenced the incidence of prolonged labour in group I. A prolonged latent phase has previously been shown to be independently associated with an increased incidence of caesarean section and other labour abnormalities ${ }^{23}$. Malone et al. ${ }^{9}$ reported that less advanced cervical dilatation on admission appear to be most important predictor of prolonged labour. His findings is also supported by the present study.

Holmes et al. ${ }^{6}$ found greater frequencies of use of oxytocin and epidural analgesia by women presenting earlier in labour compared to women in active labour. Jennifer et al. ${ }^{10}$ supported it and concluded that early admitted group is associated with increased rate of augmentation with oxytocin. The present study also shows a higher percentage of women needed oxytocin for augmentation both in group I and group II $(62.9 \%$ vs $56 \%)$ but difference did not reach statistical significance. Augmentation with oxytocin has been advocated when the progress of labour falls behind that which would be considered optimal. This vague definition reflects the wide variations in clinical practices currently in operation ${ }^{1}$. According to Richard Hayman ${ }^{1}$ oxytocin augmentation during latent phase dose not result in an increase in the vaginal delivery rate, rather a ten-fold increase in the incidence of caesarean delivery and a three-fold increase in low- Apgar score. The present study also supports it in that caesarean section was more in augmented women when they were in group I compared to group II $(59.1 \%$ vs $28.6 \%$ ). This is again in consistent with study by Rahnama et al. ${ }^{11}$ where the rate of caesarean section in the women who were augmented was greater when they were in latent phase than in active phase of labour ( $54 \%$ vs $23 \%$ ).

Women destined to have caesarean deliveries may have different labour experiences than those destined to have a vaginal delivery. Regarding analgesia in the current study a significantly higher percentage of women needed labour analgesia in early admitted group compared to late admitted group $(p<0.05)$. Need for more labour analgesia has been linked to dysfunctional labour (Alexander et al. ${ }^{18}$. This pain difference may influence the women with dysfunctional labour patterns to go to hospital sooner than women experiencing a normal labour.

Rahnama et al. ${ }^{11}$ observed the effect of timing of admission in labour unit on the method of delivery and resulted in that the number of caesarean deliveries was greater in women admitted in latent phase than in active phase of labour. Several studies ${ }^{11,12,17,20,21}$ including the present study have corroborate with this finding and demonstrated that caesarean 
section are more common when women admitted in early compared to late.

Leitch and Waker ${ }^{19}$ demonstrated failure to progress remain the major indication underlying the decision to perform caesarean section followed by foetal indication. The present study and other two studies ${ }^{20,21}$ also reflects the same. Here major indication of caesarean section was dystocia which included failure to progress followed by foetal distress. Stacy and peter ${ }^{3}$ observed that dystocia is currently the most common indication of primary caesarean section. But this is not consistent with the findings of Jahan ${ }^{22}$ who found foetal distress as the main indication for caesarean section.

Regarding neonatal outcome, infant birth weight were compared between two groups in the present study, but failed to show any significant difference (mean $3.0 \pm 0.3 \mathrm{~kg}$ vs $2.9 \pm 0.3 \mathrm{~kg}$ ). Mean infant birth weight difference between two groups was insignificant by other studies also 10,12 .

With regard to birth asphyxia of baby, Parvin ${ }^{20}$ and Rahman ${ }^{21}$, found a high proportion of baby from group I asphyxiated than baby from group II (71.3\% and $62.5 \%$ respectively). In contrast only a small proportion of babies were asphyxiated in the present study, $5.7 \%$ from group I and $4.0 \%$ from group II and mean Apgar difference was statistically insignificant. . It is presumed that difference in outcome regarding asphyxia might have influenced by the strict exclusion criteria of the present study which enrolled only low risk term gravidas.

Chelmow et al. ${ }^{23}$. found higher estimated blood loss in patients with prolonged labour after controlling for mode of delivery. Observation of the present study are not different than those of Chelmow et al. ${ }^{17}$ in that $\mathrm{PPH}$ found in $5.7 \%$ cases, who were all from early admitted group which is also the group where labour was prolonged. However, no significant difference regarding $\mathrm{PPH}$ found between two groups by Jennifer et al. ${ }^{10}$

The present study explored that, the mean duration of post partum hospital stay was (3.0 \pm 1.6 ) days in women of early admission group. This was significantly longer than that of late admitted group. This observation is supported by Hemminki and Simmuka , ${ }^{17}$ who also found longer postpartum hospital stay in early presenter group.

The timing of the onset of labour may be subject to bias in the present study as it was based on labouring women's statement.In addition, this study could not give information about the women who attended earlier in labour but admission was deferred and whether any beneficial effect of deferred admission regarding outcome. This issue was addressed in Holmes et al. ${ }^{8}$ study that found a lack of beneficial effect of deferred admission suggests that the increased intervention associated with early admission is a result of intrinsic maternal or obstetric characteristics and may not be due to unnecessary medical intervention.Indeed, it could be argued that this group of women are at higher risk of caesarean section and may benefit from early admission and close monitoring.

\section{Conclusion:}

The current study have shown that women admitted in latent phase of labour are more likely to have prolonged labour, need for analgesia and subsequently there is increased incidence of caesarean section, $\mathrm{PPH}$ and postpartum hospital stay compared to women admitted in active phase of labour. However it is not clear whether inherent labour abnormalities resulted in latent phase presentation and subsequent outcome difference or just early presentation in hospital resulted in difference in outcome between two groups of women.

Therefore, before recommending that this group of women is at higher risk of caesarean section, a larger good-quality, randomized, prospective trial will be necessary to attain the power needed for a definitive statement on this regard. 
Original Article

\section{References}

1. Richard Hayman, Poor progress in labour. Obstetrics and Gynecology. An evidencebased text for MRCOG. Arnold. 338 Euston Road. London NWI 38H. 2004:347-356.

2. Richard Hayman. Caesarean section. Obstetrics and Gynaecology. An evidencebased text for MRCOG. Arnold. 338 .Euston Road: London NWI 38 H; 2004: 381-390.

3. Strehow S, Uzelac $P$. Complications of labour \& Delivery. Current obstetrics \& Gynaecology. $10^{\text {th }}$ edition. McGraw-Hill companies. 2007: 432-440.

4. Gross M, Haunschild T, Stoexen T, Mathner V, Guentar H. Women's Recognition of the spontaneous onset of labour. Birth 2003; 30: 267-271.

5. Albers L. Rethinking dystocia: Patience please MIDRIS Midwifery Digest 2001;11:351-353.

6. Paul Holmes, Lawrene W. Oppenheimer, Shi wu wev. The Relationship between cervical dilatation at initial presentation in labour and subsequent intervention. British Journal of obstetrics and Gynecology 2001; 108:11201124.

7. Wuitchik M, Baikal D, Lipshitz J. The clinical significance of pain and cognitive activity in latent phase. Obstetrics Gynecology 1989; 73:33-42.

8. Mac Niven PS, Williams JI, Hodnett E, Kaufman K, Hannah ME. An early labour assessment program. A randomized controlled trial. Birth 1998; 25(1): 5-10.

9. Fergal $D$ malone, $M B$, Michael Geary, MB, David Chelmow, MD, John stronge, MD, Peter Boylan, MD, And Mary E Dalton, MD. Prolonged labour in nulliparous: lessons from the active Management of labour. Obstetrics \& Gynecology 1996; 88(2):211-5.

10. Jennifer L Bailit, MD, MPH, Le Roy Dierker, MD, May Hsieh Blanchard, MD, Brian M Mercer MD. Outcomes of women presenting in active versus latent phase of spontaneous labour. Obstetrics \& Gynecology 2005;105:7779.

11. Rahnama P, Ziaei S, Faghihzadeh S. Impact of early admission in labour on method of delivery. Int J Gynaecol Obstet 2006; 92(3):217-220.

12. Impey Hobson J, O' Herlihy C. Graphic analysis of actively managed labour: Prospective computation of labour progress in 500 consecutive nulliparous women in spontaneous labour at term. Am J obstet Gynecol 2000; 183: 438-443.
13. Harold Gee. Routine intrapartum care; an overview. Obstetrics \& Gynecology. An evidence-based text for MRCOG. Arnold. 338 Euston Road. London NWI 38B. 2004: 276283.

14. Melmed $H$, Evans M. Predictive value of cervical dilatation rate in primipara labour. Obstet Gynecol 1976; 47(5): 511- 5.

15. Evans MI, Lachman E, Kral S, Melmed $H$. Predictive value of cervical dilatation in labour in multiparous women. Isr J Med Sci. 1976; 12(12): 1399-1403.

16. Dutta DC. Prolonged labour, obstructed labour, Dystocia caused by fetal anomalies. Textbook of obstetrics. $6^{\text {th }}$ edition. New central Book Agency $(P)$ Ltd. 2006:402-410.

17. Hemminki E, Simukka R. The timing of hospital admission and progress of labour.Eur J Obstet Gynecol Reprod Biol 1986;22(1-2):8594.

18. Alexander JM, Sharma SK, McIntire DD, Wiley $\mathrm{J}$, Leveno $\mathrm{KJ}$. Intensity of labour pain and caesarean delivery. Anesth Analg 2001;92:1524-8.

19. Leitch CR, Walker JJ. The rise in caesarean section rate: the same indications but a lower threshold. British Journal of Obstetries and Gynaecology 1998;105: 621-626.

20. Dr. Zakia Parvin. Cervical dilatation of initial presentation in labour and subsequent outcome- a prospective study. [dissertation] BCPS. 2003.

21. Dr. Tamanna Rahman. A prospective study on the relationship between cervical dilatation at initial presentation in labour and subsequent outcome. [dissertation] BCPS. 2007.

22. Jahan Rownak. Clinical profile and outcome of labour in primi in a series of 100 cases in IPGMR. [dissertation]BCPS. 1996.

23. Chelmow D, Kilpatric SJ, Laros RK. Maternal and neonatal outcome after prolonged latent phase.Obstet Gynecol 1993;81(4):486-489. 